Mirai. Estudios Japoneses

ISSN-e: 1988-2378

http://dx.doi.org/10.5209/MIRA.57116

\title{
Japón imaginado. El imaginario manganime y la peregrinación mediática en el marco de la estrategia «Cool Japan»
}

\author{
Dr. José Andrés Santiago Iglesias ${ }^{1}$
}

Resumen: En apenas tres décadas, las voces manga y anime han pasado a formar parte de nuestro lenguaje habitual, sin necesidad de aclaraciones previas. De manera paralela, en los últimos años se ha acentuado en todo el mundo un fenómeno - que si bien no es nuevo- ha resultado en la explosión turística de localizaciones ligadas a series de ficción y producciones de éxito de cine y televisión. El manga y - especialmente - el anime non son en absoluto ajenos a este fenómeno.

El desarrollo de un universo (world-setting) minucioso es algo intrínseco a la naturaleza de manga y anime. El gusto por los detalles y la meticulosidad de los universos descritos posibilitan la inmersión del lector y la comunión de este con los personajes de la historia (Kelts, 2006). Más aún, la existencia de Japón como país real, más allá de los relatos del manga y el anime, aporta un nuevo nivel de profundidad a las historias de ambos medios.

En los últimos años el Gobierno Japonés así como instituciones regionales y locales han empezado a explotar el potencial turístico de manga y anime por igual, todo ello bajo el paraguas de Cool Japan, la estrategia de branding nacional del gobierno acuñada durante la primera década del siglo XXI.

Palabras clave: Manga; anime; Cool Japan; peregrinación mediática.

\section{[en] Imagined Japan. Manganime imaginarium and media pilgrimage within the «Cool Japan» campaign}

\begin{abstract}
In the last decades, the words manga and anime have become part of our everyday language, no longer requiring further clarifications. Meanwhile, in recent years, a worldwide phenomenon has intensified: film locations from famous fiction TV dramas and blockbusters have become touristic hotspots. Manga and anime are not oblivious to this boom.

The depiction of rich and detailed world-settings is one of the foundations of manga and anime, coded within their DNA. A well-built world-setting enables the connection between the reader/spectator and the story being told (Kelts, 2006). On top of that, the fact that Japan is indeed a real place beyond manga and anime's fictional locations provides a new level of meaning to the stories in both media.

Over the last years, the Japanese government, as well as regional and local councils, have begun to benefit from the touristic potential of manga and anime under the umbrella of "Cool Japan", the national branding campaign addressed by the government in the early 21 st century. This paper will address how this phenomenon develops within the Cool Japan campaign.
\end{abstract}

Keywords: Manga; anime; Cool Japan; media pilgrimage.

Sumario. 1. El medio japonés por antonomasia. 2. Cool Japan. 3. Japón imaginado. 4. La paradoja de Cool Japan.

Cómo citar: Santiago Iglesias, J. A. (2017). Japón imaginado. El imaginario manganime y la peregrinación mediática en el marco de la estrategia «cool japan», en Mirai. Estudios Japoneses 1(2017), 253-262.

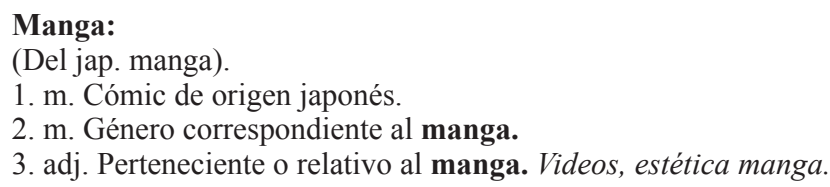

1 Departamento de Debuxo (Facultade de Belas Artes) - Universidade de Vigo. jsantiago@me.com 


\section{El medio japonés por antonomasia}

En apenas tres décadas, las voces manga, anime y otak $u^{2}$ han pasado a formar parte del lenguaje habitual, sin necesidad de aclaraciones previas. En la vigésima tercera edición del Diccionario de la Real Academia Española de la Lengua (2014) se define escuetamente manga como "Cómic de origen japonés". A mediados del año 2012, la Real Academia Española de la Lengua decidió incluir la palabra manga en el Diccionario, dejando patente la incorporación plena de este término nipón al léxico español. Sin embargo, el agrado inicial de los aficionados se transformó en decepción al comprobar cómo, en su primera acepción, se refería al manga como un "Género de cómic de origen japonés, de dibujos sencillos, en el que predominan los argumentos eróticos, violentos y fantásticos". Esta definición, alejada de la realidad del manga en España, parecía un calco de la interpretación que por entonces ofrecía el Diccionario de Oxford en lengua inglesa: "Género japonés de caricaturas y cómics, de temática fantástica o de ciencia ficción y que en ocasiones incluye material violento o sexualmente explícito". En la actualidad, algunos investigadores amplían mucho más la interpretación del término, incluyendo cualquier tipo de cómic de influencia japonesa o 'estilo manga'; un concepto interesante desde una óptica transcultural, pero impreciso y de difícil encaje en la creciente estrategia de branding cultural iniciada por el gobierno nipón. En cualquier caso, la propuesta inicial recogida por la RAE - muy peyorativa - obtuvo como respuesta un clamor por parte de investigadores, autores y aficionados en medios de comunicación y redes sociales. La RAE optó por sustituir esa definición por la que figura en la actualidad, aséptica y sin matices, pero más acorde con la realidad del medio en nuestro país: "Cómic de origen japonés".

A nivel artístico, Japón siempre ha sido reconocido por la tradición de sus pinturas y policromoxilografías ukiyo-e, por la poesía haiku, las artes marciales, la cerámica o la filosofía zen. Puede que para muchos, hoy en día el estandarte de las manifestaciones artísticas japonesas recaiga sobre su arquitectura, el diseño o la moda, sus jardines, la literatura o el cine. No obstante, se ha venido omitiendo de este singular ranking cultural las que sin duda son sus manifestaciones número uno, el manga y el anime, que muchos consideran como "el medio japonés por antonomasia"3. La presentación de Tokio 2020 como cierre a los juegos celebrados en Río de Janeiro constituye el más claro ejemplo de esta realidad. Los juegos olímpicos son un evento turístico de primera magnitud, escaparate de los principales atractivos de una nación, y por ese motivo los países organizadores suelen poner especial énfasis en aquellas facetas de la cultura, arquitectura, gastronomía o tradición deportiva que pueden resultar más atractivos para un público global. La presentación de Tokio 2020 concedió un papel central a la cultura manganime, muy por encima de otras manifestaciones. La importancia del manga y el anime no puede entenderse sino como consecuencia lógica de la omnipresencia de ambos en todas las facetas de la vida diaria y laboral, y su capacidad para influir en manifestaciones más 'selectas' conservando su condición como medios populares y de masiva diversificación. La

2 En el presente escrito se emplea “cultura otaku” en su concepción occidental y más divulgativa (ajena a los matices que posee la voz en Japón), entendida como una subcultura pop centrada en el manga, el anime y los videojuegos japoneses. Se trata de un concepto global, desposeído de connotaciones de la voz nipona otaku bunka.

3 BERnd, Jacqueline (1996): El fenómeno manga. Barcelona: Ediciones Martínez Roca, p. 9. 
chilena de Ōzora Tsubasa ${ }^{4}$, las calles de Ghost in the Shell, Doraemon, Hello Kitty, o el Primer Ministro Shinzo Abe caracterizado como Mario en el video Warming Up! de Tokio 2020 son un reflejo de todo ello. La inclusión de estos referentes de la cultura otaku puso de manifiesto dos grandes cuestiones: el reconocimiento definitivo del manga y el anime como parte fundamental de la cultura japonesa ${ }^{5}$; y el atractivo de estos personajes para atraer a aficionados de todo el mundo hacia Japón.

De manera paralela, en los últimos años se ha acentuado en todo el planeta un fenómeno - que si bien no es nuevo- ha resultado en la explosión turística de localizaciones ligadas a series de ficción y producciones de éxito de cine y televisión. Los lugares donde se graban escenas emblemáticas de series como Game of Thrones o películas como The Lord of the Rings se convierten a menudo en puntos de peregrinaje para los fans de las respectivas sagas, con el consiguiente desarrollo de la industria turística local y regional. Asimismo, hay películas y series donde la propia ciudad es tan protagonista como los personajes. El manga y - especialmente- el anime no son en absoluto ajenos a este fenómeno.

Por todo ello y en el presente artículo se aborda brevemente la creciente importancia de la cultura manga y anime en la industria turística japonesa, y el papel fundamental que juegan dos características de ambos medios en el desarrollo y promoción de la misma: la existencia de world-settings minuciosos y la capacidad inmersiva de estos metamundos gracias al referente real que es el propio país. Asimismo, deseo subrayar el papel del manganime dentro de la estrategia de branding cultural Cool Japan centrándome en lo que a mi entender son tres graves errores de aproximación a ambos medios: la ausencia de las opiniones de los aficionados occidentales como parte de la iniciativa gubernamental, al no tener en cuenta sus puntos de vista; el desarrollo de un mapa de lugares de peregrinación limitado y ajeno a buena parte de los intereses reales de los fans, obviando los mecanismos de distribución de manga y anime en los respectivos países; y por último, la incapacidad para reconciliar lo local y lo global en el presente contexto transcultural.

\section{Cool Japan}

La iniciativa Cool Japan es el gran proyecto del gobierno japonés de capitalización de industrias culturales y sus manifestaciones bajo un único paraguas: una campaña de branding cultural mediante el fomento y promoción activa de contenidos e industrias culturales. Cool Japan es un intento por transformar el modelo productivo basado en la fabricación de bienes - y resumido en la sempiterna etiqueta Made in Japan - en favor de un mayor desarrollo y creación de propiedad intelectual. La idea de Cool Japan se ampara en el concepto de soft power acuñado por Joseph Nye y que en 2002 Douglas McGray aplicó con acierto para traducir la política cultural de Japón en el mundo, en un artículo de obligada lectura en el Foreign Policy ${ }^{6}$. El

4 Ōzora Tsubasa es el protagonista del manga de Yōichi Takahashi (y del anime homónimo) Captain Tsubasa, publicado en la revista Shōnen Jump entre 1981 y 1988. TAKAHASHI, Yōichi (1981): Captain Tsubasa. Tokio: Shūeisha.

5 El video de Tokio 2020 es revelador, por cuanto anticipa algunas de las cuestiones presentadas en este escrito: las fronteras entre ficción y realidad se diluyen y la 'subcultura' otaku, se convierte directamente en cultura. El manga y el anime son parte inseparable de la realidad cotidiana de Japón.

6 McGraY, Douglas (2002): “Japan's gross national cool”. En: Foreign Policy, Mayo-Junio 2002, Washington, pp. 44-55. 
concepto de soft power aplicado al caso japonés explica el porqué del atractivo de este país para millones de ciudadanos de todo el mundo; un modelo definido por ser poco agresivo, pero muy eficaz. Atendiendo a esta premisa, Japón habría logrado explotar satisfactoriamente el ideal de país moderno, democrático, tolerante y pacifista —una idea arraigada en la Constitución de la Paz de 1947 — y culturalmente seductor, y con ello ha logrado que otros hagan lo que desea por medio de la atracción y el interés, en lugar de emplear la fuerza o el soborno.

Varias publicaciones de JETRO (Japan External Trade Organization) y de METI (Ministry of Economy, Trade, and Industry) vienen apuntando desde el año 2005 a esta idea de unificar cultura e industria nacional, y de potenciar, más si cabe, el rol internacional de Japón en el mundo a través de productos culturalmente atractivos. Dentro de este contexto y en los últimos años se ha empezado a explotar el potencial turístico y comunicador de manga y anime por igual. Esta misma estrategia ha terminado siendo adoptada por instituciones regionales y locales con igual fortuna. No sólo se han multiplicado las carismáticas mascotas yuru-kyara para representar regiones, instituciones o edificios notables (que en algunos casos ya generan ingresos multimillonarios en concepto de merchandising) sino también el uso de personajes de series populares. Héroes del manganime son ahora embajadores de determinadas prefecturas y atracciones turísticas. El célebre cartel con el personaje de Shin Seiki Evangelion ${ }^{7}$ promocionando las aguas termales en la región de Hakone bajo la leyenda "Fusion with tradition" (2010) es un ejemplo particularmente revelador y constituye un paso más en esta hibridación entre realidad y ficción. Al mismo tiempo este cartel ilustra uno de los principales clichés de Japón, la idea del país exótico regido por la idílica paradoja de tradición y modernidad que coexiste en la vida diaria ${ }^{8}$.

\section{Japón Imaginado}

El desarrollo de un universo (world-setting) minucioso es algo intrínseco a la naturaleza de manga y anime. A nivel estructural, el anime se caracteriza por el uso metonímico del intertexto (o yuxtaposición de referencias intertextuales) para la construcción estética de personajes y universo, así como por forzar el conflicto 'personaje versus universo' con una finalidad puramente narrativa9. En el caso del manga, el carácter incisivo con el que se insertan lugares en algunas páginas o la manera en la que fluye la narración en determinadas secuencias parecen buscar deliberadamente el comportarse como balizas para localizaciones dignas de ser visitadas en el futuro por los aficionados a esa serie.

El manga y el anime posibilitan la construcción de un metamundo pormenorizado, brillantemente recreado, que facilita la inmersión del lector en un imaginario de fantasía. El gusto por los detalles y la meticulosidad de los universos descritos posibilitan la sumersión del lector y la comunión de este con los personajes de la historia ${ }^{10}$.

\footnotetext{
Estudio Gainax, 1995.

8 SABre, Clothilde (2016): "French Anime and Manga Fans in Japan: Pop culture tourism, media pilgrimage, imaginary". En: International Journal of Contents Tourism, Vol. 1.1, Sapporo, p. 6.

9 Sunn, Stevie (2013): The Anime Paradox: Patterns and Practices through the Lens of Traditional Japanese Theater. Leiden and Boston: Global Oriental.

10 Kelts, Roland (2006): Japanamerica: How Japanese Pop Culture has Invaded The U.S. NY: Palgrave Macmillan.
} 
Además, la existencia de Japón como país real, más allá de los relatos del manga y el anime, aporta un nuevo nivel de profundidad a las historias de ambos medios.

Tal y como explica Macias: "Los fans de El Señor de los Anillos no pueden viajar a la Tierra Media, al igual que los fans de Harry Potter no pueden ir a Hogwarts. Pero uno puede ahorrar y comprar un billete a Tokio" ${ }^{11}$. Incluso cuando la realidad no se ajusta a las expectativas de estos aficionados, estas terminan siendo sustituidas por nuevos alicientes que brinda dicha cultura japonesa.

Clothilde Sabre emplea el concepto de media pilgrimage (que podríamos traducir como peregrinación mediática) para describir el fenómeno de cómo el imaginario específico del manganime empuja a numerosos aficionados de ambos medios a viajar a Japón para experimentar en primera persona lugares relacionados con este tema de interés y —lo que quizás es más importante y significativo - localizaciones precisas que aparecen en sus mangas y anime favoritos. El concepto usado por Sabre - y por muchos otros investigadores con anterioridad - no es tan importante como la actitud que describe: un numeroso conjunto de aficionados que viajan a Japón atraídos por la cultura otaku y por localizaciones concretas que tienen especial relevancia en las narrativas de ficción que aparecen en el manga y el anime de su interés. Todo ello se basa en la dilución de la frontera entre realidad y ficción mediática: al visitar en el mundo real el punto concreto en el que se desarrolla un evento importante en la ficción se establece una conexión más intensa entre ambos planos. Este tipo de conexiones intermediales son extensibles a otros fenómenos cinematográficos como El Señor de los Anillos o Juego de Tronos, con miles de aficionados peregrinando a los lugares de rodaje de estas producciones. La gran diferencia, y que hace del fenómeno manga y anime un caso especialmente singular, es que los aficionados no viajan realmente a la Tierra Media o a Westeros, sino a lugares en los que se recrearon dichos parajes. Sin embargo, cuando un fan del manga y del anime emula a los protagonistas de Love $H_{i n a^{12}}$ en la Tokyo Daigaku, a los personajes de numerosos manga de CLAMP en la Torre de Tokio, o busca los bares y calles en las que desarrollan las aventuras de City Hunter, Kimagure Orange Road o Bakuman, entre muchos otros, participa de algún modo de la misma experiencia que sus héroes de ficción, y conecta definitivamente el imaginario del manganime con el plano de realidad que habitamos.

Sabre acuña el concepto de fantasised Japaneseness ${ }^{13}$ para explicar este fenómeno, muy cercano al título de 'Japón Imaginado' que articula este escrito:

Los fans construyen sus propios mundos imaginarios a partir de referencias colectivas. [...] Ser un "fan" consiste en sentir que uno pertenece a una comunidad específica y, al mismo tiempo, ser poseedor de un universo íntimo y personal derivado de una obra objeto de admiración en el que diferentes aficionados pueden proyectar sus propias fantasías ${ }^{14}$.

Japón es el país de donde provienen el anime y el manga, es el país productor de ambos medios y es, en muchos casos, el marco cultural y espacio-temporal en el

11 Macias, Patrick; y Machiyama, Tomohiro (2004): Cruising the Anime City: An Otaku Guide to Neo Tokyo. Berkeley (California): Stone Bridge Press, p. 118.

12 Akamatsu, Ken (1998): Love Hina. Tokio: Kōdansha.

13 SABre, Clothilde (2016): "French Anime...", op. cit. p.6

14 Ibidem. 
que se desarrollan las narraciones descritas. Por ese motivo Japón es al mismo tiempo generador del producto consumido y el world-setting, entendido a la manera de Suan $^{15}$, el constructo sobre el que se levanta este imaginario en el que las narraciones tienen lugar. Japón otorga veracidad y fisicidad a este entorno liminal; un lugar sobre el que soñar y que al mismo tiempo los aficionados pueden visitar para experimentarlo de primera mano. Por todo ello, Japón está en el centro de esta cultura otaku, pero no como consecuencia de la estrategia de branding cultural de Cool Japan, sino porque el mundo imaginario que ocupan estas narrativas no puede entenderse sin el propio Japón.

Teniendo en cuenta los lugares visitados en Japón por aficionados del manganime podemos establecer una cuádruple tipología de puntos de peregrinación ${ }^{16}$ :

1. Lugares dedicados específicamente a la cultura manganime, como el Museo Ghibli, El Kyoto International Manga Museum, el Comiket, el Osamu Tezuka Manga Museum, etc.

2. Tiendas y negocios directamente relacionados con la venta de productos sobre manganime, merchandising o con la cultura otaku, como maid-cafes. En estos casos, tal y como explica Sabre ${ }^{17}$, "se mezcla la actitud de ser un turista $\mathrm{y}$ un cliente, y demuestra que este tipo de tiendas son para los turistas sitios que les permiten sumergirse físicamente en sus fantasyscape"18.

3. Lugares como la entrada del parque Yoyogi y los barrios de Harajuku, Akihabara ${ }^{19}$ y Shibuya, considerados puntos icónicos de la cultura otaku en Japón, y que a menudo presentan una gran concentración de elementos del segundo grupo.

4. Por último, lugares sin ninguna mención directa a la cultura otaku, pero que han aparecido en obras notables de manga o anime y por tanto son objeto de peregrinación de aficionados de todo el mundo. Estos lugares son los más interesantes desde el punto de vista de este escrito, toda vez poseen un valor y una significación más grande para aquellos aficionados que las visitan, y permiten una inmersión más profunda en el imaginario de fantasía del manganime.

Curiosamente, la estrategia Cool Japan se centra de manera casi exclusiva en las localizaciones del primer grupo y, de vez en cuando, en las del segundo y tercero; pero a menudo ignora el cuarto gran grupo de esta tipología que engloba las localizaciones con un significado más profundo y personal para muchos de los aficionados hardcore que viajan como turistas a Japón. Existe, pues, una brecha significativa entre la idea que de Cool Japan tiene del turista occidental y la propia experiencia de dichos aficionados.

15 SuAn, Stevie (2013): The Anime Paradox...op.cit..

16 Una tipología muy similar a la que plantea Sabre, compuesta por tres grupos, en su caso, pero con una casuística y criterios de clasificación similares a los aquí propuestos.

17 SABre, Clothilde. (2016): "French Anime...", op. cit. p. 10.

18 El concepto de fantasyscape fue acuñado acuñado por Napier, en alusión a los mundos interiores paralelos a la realidad, en los que el aficionado puede entrar y salir a su completa discreción. NAPIER, Susan (2007): From impressionism to anime: Japan as fantasy and fan cult in the mind of the west. New York: Palgrave Macmillan.

19 El problema de Akihabara — en el que abunda Galbraith — es la paulatina transformación de esta zona de Tokio en una suerte de 'parque de atracciones' turístico, un simulacro del Japón real no tan distinto a las atracciones de Harry Potter en Universal Studios. Galbraith, Patrick W. (2010): “Akihabara: conditioning a public otaku image". En: Mechademia, 5. Minnesota, pp. 210-231. 
El turismo ligado al manganime en Japón está fuertemente vinculado a las consideraciones del fandom local, esto es, en sus respectivos países, y de cómo el manga y el anime se expandieron cultural y comercialmente en estos mercados - una faceta bastante ignorada dentro de la iniciativa Cool Japan, que tiende a generalizar los gustos del aficionado europeo. Existen numerosos lugares considerados 'de culto' por parte de aficionados occidentales que los organismos japoneses omiten en las guías y recorridos oficiales, ofreciendo una imagen bastante distorsionada de lo que el fan más entusiasta pretende encontrar en su viaje a Japón. Existen estudios sobre este tema, pero muchos de ellos se centran en el propio mercado interno japonés; no obstante, para evaluar el mercado europeo y español es necesario contemplar la dimensión transcultural del fenómeno manganime: cómo ambos medios forman parte de una cultura global y cómo se distribuyeron originalmente en España (u otros países). "Para estudiar el turismo de contenidos internacional debemos tener en cuenta la dimensión intercultural de la difusión y recepción de contenidos, porque el modo en que los aficionados se apropian de dichos contenidos a través del prisma de su propio trasfondo cultural desempeña un papel fundamental en su experiencia turística" ${ }^{20}$.

En este sentido, creo que la dicotomía de dos fases que emplea Marco Pellitteri en la monografía The Dragon and the Dazzle ${ }^{21}$ para explicar la expansión del manga y el anime en los mercados europeos es particularmente ilustrativa y de utilidad para el caso que nos ocupa.

En su libro, Pellitteri describe dos fases - que denomina poéticamente como "dragon" y "dazzle" - con respecto a cómo el anime (y por extensión el manga) se dirigen de forma activa a los espectadores occidentales. Cada fase se corresponde con una dinámica diferente; la primera fase (el dragón) se caracteriza por una aproximación del medio hacia el espectador más neutral, con una fuerte domesticación, caracterizada por productos familiares para un público occidental y adoptar la actitud más bien pasiva hacia el espectador y el mercado. Se segunda fase, en cambio, se fundamenta en la creencia de que los espectadores occidentales están familiarizados con el lenguaje visual del manga y el anime. En esta fase se hace hincapié en un producto híbrido que recuerda a un Occidente pasado a través de un tamiz japonés, con fuertes connotaciones del imaginario cotidiano nipón y un discurso más activo.

En origen, las fases descritas por Pellitteri están pensadas para describir dos etapas de expansión del manga y anime en mercados occidentales, pero podemos extrapolarlas para enfrentarlas con la actitud oficial de Japón antes y después de la puesta en marcha de Cool Japan. La contradicción estriba en que la versión ofrecida por el gobierno japonés es mucho más domesticada que lo que demandan los aficionados hardcore, que son, en definitiva, los que viajan a Japón para participar de esta experiencia de peregrinaje mediático. La primera fase, dirigida a un público general y profundamente domesticada tiene mucho más que ver con la estrategia de promoción que Cool Japan está poniendo en práctica. Así pues, las exigencias de aficionados de un producto más fiel al original nipón se ven desvirtuadas en buena medida por las actuaciones institucionales que, difícilmente, pueden satisfacer las demandas del fandom occidental. Sabre afirma que los aficionados del manganime que viajan a Japón tienen la necesidad de sentirse familiares con la cultura y mentali-

\footnotetext{
SABre, Clothilde (2016): "French Anime...," op. cit. p. 2.

Pellitteri, Marco (2010): The Dragon and the Dazzle: Models, Strategies and Identities of Japanese Imagination. Latina: Tunué Editori dell'imaginario.
} 
dad japonesas para poder entender realmente el manga y el anime. Es por ese motivo que no termina de cuajar la versión profundamente domesticada de Cool Japan, un sucedáneo 'descafeinado' para un fandom que demanda mucho más que un decorado "simulacral", sino una experiencia totalmente inmersiva.

\section{La paradoja de Cool Japan}

Son numerosos los investigadores que cuestionan el modo en el que Cool Japan proporciona una imagen distorsionada y artificial de la cultura otaku, que poco o nada tiene que ver con los aficionados japoneses u occidentales. Las estrategias de branding cultural en general manipulan y desvirtúan las prácticas del fandom en favor de actuaciones mucho más estandarizadas. Hasta este punto hemos visto las que, en mi opinión, constituyen dos taras importantes de la iniciativa del branding cultural Cool Japan a la hora de entender el rol del manga y el anime para el desarrollo y promoción de la industria turística japonesa. Por una parte, Cool Japan plantea una perspectiva extremadamente domesticada que ignora en parte los verdaderos intereses de los aficionados. Por otra, no tiene en cuenta las diferencias nacionales, obviando los mecanismos de distribución de manga y anime en los respectivos países. Pero además de estas dos taras, la propia idea de Cool Japan sufre como resultado de una tensión dicotómica entre nacional y transcultural. Cool Japan presenta un cisma entre la reivindicación del ADN japonés en las producciones de manga y anime y su inserción cada vez más profunda en el marco de una cultura global - elevando la cuestión acerca de si el manga y el anime pueden ser entendidos como un producto $100 \%$ japonés en el contexto actual.

Cool Japan adolece de una falta de perspectiva transcultural — incapaz de reconciliar lo local y lo global — desde el mismo instante en que no tiene en consideración el fenómeno del manga y el anime como un fenómeno global. La capacidad del manga para permear en otras manifestaciones artísticas o influenciar a creadores de todo el mundo tiene un efecto globalizador que puede entrar en conflicto con algunas de las reivindicaciones de esta iniciativa de branding cultural. Si se puede plantear el estudio del manga atendiendo exclusivamente a su forma, esta misma formulación permitiría, en último extremo, que cualquiera pudiese hacer manga, siempre y cuando siga con meticulosidad y precisión las directrices formales que lo definen. Esta posibilidad enraíza profundamente con la creencia de la naturaleza transcultural del manga y su capacidad para establecer puentes en todo el mundo, tanto por el rigor de la forma como por sus capacidades intertextuales. Sin embargo, esta dilución cultural no interesa a la estrategia de promoción del Gobierno japonés, para quien el manga destaca como producto que contribuye a la imagen internacional del país.

En el caso del anime, la participación de varios equipos con sedes en diferentes países dificulta aún más este debate. Tal y como apunta Suan, a pesar de que a menudo se acuña bajo una etiqueta común - anime - no hay un denominador único que sirva para identificar el conjunto de producciones animadas para televisión en Japón. Sin embargo, sí que se puede apuntar inmediatamente — incluso para aquellos ajenos al fandom que rodea este medio - a una similitud entre este tipo de producciones. Aun cuando muchas de ellas presenten enormes diferencias en estilo gráfico y narrativa, se distinguen inmediatamente patrones que se repiten de manera inequívoca en este tipo de producciones animadas. Asimismo, existen numerosas metarreferencias 
que hacen de este medio una red interconectada, con independencia de estudios o directores; una identidad que hace que el anime sea anime. Ahora bien iradica esta identidad en la repetición de estas convenciones reconocibles o en el país o equipo de producción? En este sentido, el branding del anime como anime y del manga como manga también se ve amplificado por campañas de promoción cultural como Cool Japan. Explica Suan:

Estas semejanzas estilísticas se exageran a consecuencia de una distribución global y el posicionamiento comercial del anime (a través de campañas de branding nacional como Cool Japan) como un producto japonés de cultura pop [...]. Esto favorece una concepción del anime como un producto local (japonés), y por tanto anime pasa a definirse como 'animación popular japonesa'. Sin embargo, el anime es, en muchos aspectos, global. En realidad, los anime 'japoneses' son el resultado de un sistema de producción transnacional funcionando desde hace décadas, donde Japón es el nodo principal de un conglomerado de estudios de producción repartidos por toda $\mathrm{Asia}^{22}$.

Y añade Suan: "La identidad del anime está conformada por estas tensiones, y su capacidad performativa se define por la tensión dinámica que existe entre unidad, codificación y lo global de una parte, y la diversidad, la variación y lo local en la otra"23. $^{23}$.

A medida que el manga y el anime se asocian de forma clara con Cool Japan, el esfuerzo por etiquetarlo como un producto cultural exclusivamente japonés se hace cada vez más patente en las instituciones oficiales. El principal inconveniente de esta estrategia estriba en lo agresivo del movimiento, percibido de forma poco amigable por autores, investigadores y colectivos sociales; monopolizando, en definitiva, la "forma" del manga y el anime, y su aptitud como portador de ideología. En ese sentido, la consideración de Suan resulta especialmente reveladora: Cool Japan no reivindica para sí trabajos individuales o producciones de determinadas compañías, ni su copyright, sino el manga y el anime como forma, abarcando de este modo cualquier producción pasada, presente o futura. El manga como medio pasa a convertirse en un producto per se, como parte del futuro de la nación. Esto pone además de manifiesto el interés inequívoco del gobierno por el valor ideológico del manga: delimitando qué discursos son aceptables - y cuales no- así como quien puede hacer manga, restringiendo en la práctica el medio a las grandes industrias editoriales que ya generan manga en la actualidad, y donde tienen fácil encaje las obras más comerciales, de menor perfil crítico o subversivo, y profundamente ancladas en un engranaje editorial en el que el gobierno lleva trabajando desde la década de 1970. Sin embargo, como explicaba Suan en el curso de una conferencia, "en el mundo actual, no hay nada como etiquetar un producto como cool para que inmediatamente deje de serlo" 24 .

22 Suan, Stevie (2017): "Anime's Performativity: Diversity through Conventionality in a Global Media-Form". En: Animation. An interdisciplinary journal, Vol 12 (1), Londres, p. 63.

23 Ibid., p. 67.

24 Suan, Stevie (2015): "Performing differently: Convention, medium, and globality from manga (studies) to anime (studies)". En: Berndt, Jaqueline (coord.): Comicology: Probing Practical Scholarship. Kioto: Kyoto International Manga Museum. 
El manga ha demostrado a lo largo de más de cien años de historia moderna su capacidad para obviar este tipo de condicionantes y articular referencias intertextuales con igual potencial crítico. En ese sentido y vistos los antecedentes, debemos creer que el manga y el anime son capaces de articular nuevas oportunidades para la industria turística japonesa más allá del corsé institucional. 